\title{
Effect of Insulin on Adiponectin and Adiponectin Receptor-1 Expression in Rats with Streptozotocin-induced Type 2 Diabetes
}

\author{
Fahaid Al-Hashem, ${ }^{*}$, Ibrahim Ibrahim, ${ }^{b}$ Nermeen Bastawy, ${ }^{b}$ Moshira Rateb, ${ }^{b}$ \\ Mohamed Haidara, ${ }^{a}$ Mohammed Dallak, ${ }^{a}$ Sanja Soskic, ${ }^{c}$ Ismaeel Bin-Jaliah, ${ }^{a}$ \\ and Esma Isenovic $c$
}

\begin{abstract}
${ }^{a}$ Department of Physiology, College of Medicine, King Khalid University, Abha 61421, P.O. Box 641 Saudi Arabia, ${ }^{b}$ Department of Physiology, Kasr Al-Aini Faculty of Medicine, Kasr Al-Aini street P.O. Box 7879 Cairo University, Egypt and ${ }^{c}$ Vinča Institute, University of Belgrade, Department for Molecular Genetics and Radiobiology, P.O. Box 522, 11001 Belgrade, Serbia
\end{abstract}

(Received January 31, 2011; Accepted April 9, 2011)

\begin{abstract}
The present study was designed to investigate the effect of insulin on insulin resistance (IR), plasma adiponectin level and expression of adiponectin receptors 1 (AdipoR1) in obese and streptozotocin-induced type 2 diabetic rats. Male Sprague-Dowley rats were randomized to control group and 3 obese experimental groups. Type 2 diabetic mellitus was induced in the $3^{\text {rd }}$ and $4^{\text {th }}$ experimental groups by given $30 \mathrm{mg} / \mathrm{kg}$ of a single dose streptozotocin via intraperitoneal injection (i.p.). Fourth group was treated with i.p. $1 \mathrm{IU}$ insulin $/ \mathrm{kg} / \mathrm{day}$ for 6 days before end of the experiment which lasts for 8 weeks while same amount of normal saline was i.p. given to other group. At the end of the study ( 8 weeks), plasma levels of adiponectin, triglycerides (TG), cholesterol, fasting blood glucose and insulin were measured. Obesity index (OI) and IR were calculated. AdipoR1 mRNA levels in the soleus muscle tissue were semi-quantitated. Hyperlipidemia, hyperinsulinemia and hyperglycemia were observed in both obese and diabetic rats, which were accompanied by hypoadiponectinemia and down regulation of AdipoR1 expression as compared to the control rats. Adiponectin was negatively correlated with all the biochemical parameters assessed. Insulin treatment significantly improved these metabolic abnormalities and effectively restored adiponectin and AdipoR1 to the control level. In conclusion, adiponectin and its receptor-associated cascade may be aberrantly regulated in both obesity and type 2 diabetes and targeting adiponectin and its receptors may offer a novel therapy against obesity and type 2 diabetes.
\end{abstract}

Key words_ adiponectin, diabetes, streptozotocin, insulin

\section{INTRODUCTION}

White adipose tissue has been increasingly recognized as an important endocrine organ that secretes a number of biologically active adipocytokines including adiponectin. ${ }^{1)}$ Adiponectin mediates its effects through at least three cell membrane receptors: adiponectin receptor-1 (AdipoR1) expressed abundantly in skeletal muscles, AdipoR2 expressed abundantly in the liver, and recently identified T-cadherin expressed primarily in vascular endothelial and smooth muscle cells. These re-

\footnotetext{
*To whom correspondence should be addressed: Department of Physiology, College of Medicine, King Khalid University, Abha 61421, P.O. Box 641 Saudi Arabia. Tel.: +966-72417879; Fax: +966-7241-8364; E-mail: fahaid999@yahoo.com
}

ceptors activate adenosine mono phosphate protein kinase (AMPK) and peroxisome proliferatoractivated receptor- $\alpha$ (PPAR- $\alpha$ ) upon adiponectin binding, thereby leading to fatty acid oxidation and glucose uptake. ${ }^{2)}$

Circulating adiponectin level $(1.9-17.0 \mu \mathrm{g} / \mathrm{ml})$ in healthy adults accounts for $0.01 \%$ of total plasma proteins. ${ }^{3,4)}$ Many factors affect plasma adiponectin concentration. Among these, circadian rhythm has been demonstrated to regulate diurnal and pulsatile secretion of adiponectin in humans; adiponectin peaks in the morning and decreases at night. ${ }^{5)}$ Moreover, plasma adiponectin level is higher in human and rodent females than in males, suggesting that sex hormones may regulate the production of adiponectin. ${ }^{6,7)}$ Another important category 
of regulators of adiponectin expression and secretion are dietary factors. Fish oils and linoleic acid have also been demonstrated to be able to increase plasma adiponectin level, ${ }^{8,9)}$ which is consistent with the fact/observation that intake of these substances results in enhanced protection against the development of diabetic mellitus (DM). In contrast, carbohydrate-rich and high-fat diets appear to decrease plasma adiponectin level. ${ }^{10)}$ In addition, plasma adiponectin concentration is negatively correlated with body mass index (BMI), insulin resistance (IR), triglyceride (TG) and low density lipoproteins (LDL) and positively correlated with high density lipoproteins (HDL). ${ }^{11)}$ Accordingly, plasma adiponectin concentration has also been found to be high in thin individuals, inflammation, and in type $1 \mathrm{DM}$, and low in type $2 \mathrm{DM}$, lipodystrophy and in obese individuals. ${ }^{12)}$

Given the importance of adiponectin and its receptors in fat and glucose metabolism as well as in the pathogenesis, it is warranted to have a better understanding of the regulation of adiponectin and its receptors, which may lead to development of novel preventive and therapeutic strategies for control of DM and metabolic syndrome. ${ }^{13)}$ To this end, the present study was conducted to assess the possible contribution of adiponectin in amelioration of lipid profile and IR, the metabolic abnormalities (hyperlipidemia, hyperinsulinemia and hyperglycemia) in obese and its link to the induced-type 2 diabetes in rats. In addition, the effect of insulin on adiponectin and its receptor expression was also evaluated.

\section{METHODS}

Chemicals — Streptozotocin (Trade name Zanosar) was purchased from Sigma Chemical Company (St. Louis, MO, U.S.A.). The drug was dissolved in $0.1 \mathrm{M}$ sodium citrate $(\mathrm{pH} 4.5)$. Long acting protamine zinc insulin (PZI), a premixed suspension of $30 \%$ soluble crystalline insulin and $70 \%$ isophan insulin, ${ }^{14)}$ was purchased from Nile Company (Cairo, Egypt).

Animals — Forty male Sprague-Dowley rats, 6 weeks old and 145-200 g in body weight, were used. They were kept at $22 \pm 1{ }^{\circ} \mathrm{C}$ in a $12 \mathrm{hr}$ darklight cycle in the Animal Center of Kasr Al-Aini Faculty/School of Medicine, Cairo University, with free access to food and water. Animals were randomly divided into 4 groups ( $n=10$, control, obese, type $2 \mathrm{DM}$, type $2 \mathrm{DM}$ with insulin treatment). An- imals in the control group were fed with a standard rat chow composed of: $60 \%$ soya bean, gelatin, corn powder, $3.3 \%$ crude fibers, $21.2 \%$ crude protein, $3.2 \%$ crude oil, $12.3 \%$ fish and bone powder, vitamins and minerals. Total calorie $30 \mathrm{kcal} / \mathrm{kg}$, while obesity was induced in the other three groups by feeding them with a high-fat diet (35 $\mathrm{g}$ of lard per $110 \mathrm{~g}$ of above rat chow) for 8 weeks. Type 2 DM was induced in the $3^{\text {rd }}$ and $4^{\text {th }}$ group via intra-peritoneal (i.p.) single dose injection of $30 \mathrm{mg}$ streptozotocin $/ \mathrm{kg}$. Fourth group was treated with i.p. $1 \mathrm{IU}$ insulin $/ \mathrm{kg} /$ day for 6 days before the end of the experiment which lasts for 8 weeks while other groups were i.p. treated with same amount of normal saline.

Verification of DM- DM was verified 5 days after treatment by measuring blood glucose levels following overnight fasting with the use of glucose oxidase reagent strips (LifeScan, Milpitas, CA, U.S.A.). Rats having blood glucose level $\geq 200 \mathrm{mg} / \mathrm{dl}$ were considered diabetic. ${ }^{15)}$

The experiments were conducted in accordance with Ethical Guidelines for investigations of laboratory animals and were approved by the Ethical Committee of Physiology Department at Kasr AlAini Faculty of Medicine, Cairo University.

Laboratory Analyses of Blood Samples — At the end of the 8 week study, animals were fasted overnight and retro-orbital blood samples were obtained using heparinized capillary tubes under pentobarbital $(40 \mathrm{mg} / \mathrm{kg})$ anesthesia. Plasma was prepared and stored at $-70^{\circ} \mathrm{C}$ until analyses.

Plasma insulin concentration was measured by enzyme immunoassay using a rat insulin ELISA kit (Linco Research, MO, U.S.A.) according to the manufacturer's instructions. Plasma glucose concentration was determined using a kit from Diamond Diagnostics as previously described by Trinder. ${ }^{16)}$ Plasma TG was assayed by the method previously described by Wahlefeld, ${ }^{17)}$ using a TG quantification kit from BioVision Research. Plasma cholesterol was assayed as previously described by Sundvall, ${ }^{18)}$ using a cholesterol assay kit BioAssay Systems. Adiponectin concentration was determined by ELISA using a rat adiponectin ELISA kit from Linco Research as instructed by the manufacturer.

Calculation of Obesity Index (OI) - At the end of the designated treatments ( 8 weeks), animals were weighted and the naso-anal length was measured in $\mathrm{cm}$ as previously described. ${ }^{19)}$ The OI (equivalent to BMI in humans) was calculated ac- 
cording to an equation formulated by Dubuis: ${ }^{20)}$

$$
\mathrm{OI}=\sqrt[3]{\text { weight }(\mathrm{gm})} \times 1000 / \text { naso-anal length }(\mathrm{cm})
$$

Homeostasis Model Assessment of Insulin Resistance (HOMA-IR) — The assessment of IR was performed using a mathematical model devised by Matthews, ${ }^{21)}$ based on the relationship between fasting plasma glucose and insulin:

$$
\begin{aligned}
\text { HOMA-IR }= & \{[\text { Fasting glucose }(\mathrm{mg} / \mathrm{dl}) / 18] \\
& \times \text { Fasting insulin }(\mu \mathrm{IU} / \mathrm{ml})\} / 22.5
\end{aligned}
$$

\section{Reverse Transcription-polymerase Chain Reac-} tion (RT-PCR) — At the end of the experiment, animals were sacrificed and tissue samples from soleus muscle $(30 \mathrm{mg})$ were collected and snapfrozen in liquid nitrogen until use. Total cellular RNA was extracted was from soleus muscle homogenate using SV-Total RNA isolation system kit (Promega Biosciences, Madison, WI, U.S.A.) according to the manufacturer's instructions. RTPCR of AdipoR1 gene as performed as described by Williams, ${ }^{22)}$ using a RT-PCR kit from Stratagene (La Jolla, CA, U.S.A.). Briefly, extracted RNA was reversely transcribed into cDNA using a reverse primary specific to the rat AdipoR1 gene in $36 \mu l$ reaction. The synthesized first strand cDNA was amplified by PCR using a pair of primers (forward: 5'-AAT GTTTCAGTGCAGAG-3' and reverse: 5'-TTG GGATGATGTCGGGAC-3') designed according to the rat AdipoR1 gene for 35 cycles. The PCR products were electrophoresed on a $1.5 \%$ agarose gel and UV visualized after staining with ethidium bromide. AdipoR1 mRNA levels were semiquantitated by using gel documentation system (Biometra, Goettingen, Germany).

Statistical Analysis — Data presented as mean \pm S.D. were analyzed by unpaired $t$-test or one-way analysis of variance (ANOVA) together with multiple comparison test whenever appropriate. Pearson Correlation was used to assess the relationship between different variables. Difference was considered significant when $p \leq 0.05$. All analyses were performed using the statistical package Statistical Package for the Social Sciences (SPSS) version 16.

\section{RESULTS}

\section{Changes in OI}

Figure 1 shows OI in the control and experimental groups. The OI in the control group

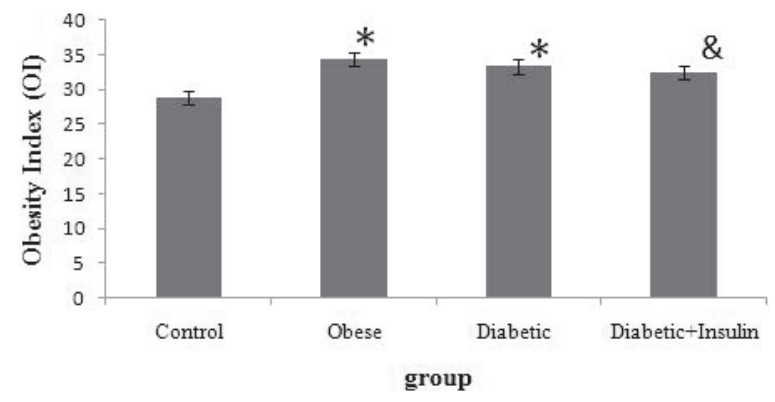

Fig. 1. OI in Control Rats and 3 Experimental Rat Groups Values are given as mean \pm S.D. and are statistically significant at $p<0.05$. *: Significant compared with the control group. \&: Significant compared with diabetic group.

was $28.9 \pm 0.42$ and it increases significantly to $34.4 \pm 3.9$ and to $33.3 \pm 4.6$ in the obese and diabetic group respectively. However, in rats that daily received $1 \mathrm{IU} / \mathrm{kg}$ of insulin; OI decrease was significant compared with the $3^{\text {rd }}$ group.

\section{Changes in Blood Biochemical Parameters}

Table 1 shows Changes in blood biochemical parameters in control and experimental groups. As compare to control; TG, cholesterol, glucose and insulin were significantly increased in obese and diabetic group rat. Also, there was a significant decrease in the concentration of adiponectin. However, treatment of diabetic group with insulin ameliorated these deleterious effects.

\section{Changes in AdipoR1 mRNA Levels}

Figure 2 shows Changes in AdipoR 1 mRNA levels $(\mu / g m$ tissue) in control and experimental groups. This was $0.33 \pm 0.06$ in control group and it decrease significantly to $0.16 \pm 0.04$ and to $0.18 \pm 0.03$ in the obese and diabetic group respectively. However, in diabetic rats that daily received $1 \mathrm{IU} / \mathrm{kg} /$ of insulin; AdipoR1 mRNA was significantly increased by $61 \%$ as compared to diabetic group.

\section{Correlation between Plasma Adiponectin and AdipoR1}

On reviewing the results of correlation to identify factors most strongly correlated with fasting plasma adiponectin concentration and AdipoR1 expression in skeletal muscle, the present study revealed that plasma adiponectin and AdipoR1 were significantly correlated negatively with the following parameters: BMI, fasting plasma total cholesterol (TC), TG, insulin, glucose levels, and HOMAIR. Interestingly, the correlation between AdipoR1 
Table 1. Plasma Concentration of Adiponectin, TG, Cholesterol, Glucose and Insulin in the Indicated Groups of Rats

\begin{tabular}{lcccr}
\hline \hline & Control & Obese & Diabetic & Diabetic + insulin \\
\hline TG $(\mathrm{mg} / \mathrm{dl})$ & $57.34 \pm 6.02$ & $74.88 \pm 7.1^{*}$ & $85.55 \pm 5.7^{*}$ & $68.55 \pm 6.4^{\&}$ \\
Cholesterol $(\mathrm{mg} / \mathrm{dl})$ & $127.37 \pm 5.5$ & $157.95 \pm 10.76^{*}$ & $173.55 \pm 11.7^{*}$ & $155.27 \pm 7.46^{\&}$ \\
Glucose $(\mathrm{mg} / \mathrm{dl})$ & $79.66 \pm 3.70$ & $141.21 \pm 18.54^{*}$ & $219.19 \pm 26.76^{*}$ & $166.44 \pm 13.87^{\&}$ \\
Insulin $(\mu \mathrm{IU} / \mathrm{dl})$ & $11.05 \pm 0.71$ & $28.52 \pm 2.31^{*}$ & $36.65 \pm 3.98^{*}$ & $19.74 \pm 1.54^{\&}$ \\
Adiponectin $(\mathrm{ng} / \mathrm{dl})$ & $6.90 \pm 1.03$ & $3.35 \pm 0.9^{*}$ & $2.45 \pm 0.74^{*}$ & $4.69 \pm 0.45^{\&}$ \\
\hline & $*$ Significant as compared to control group $(p<0.001) . \&$ : Significant as compared to the obese and diabetic \\
group $(p<0.001)$. &
\end{tabular}

Table 2. Correlations between Fasting Plasma Adiponectin with Fasting Plasma TG, TC, Glucose, Insulin, HOMA-IR and OI

\begin{tabular}{llcc}
\hline \hline & & Adiponectin & AdipoR1 \\
\hline TG $(\mathrm{mg} / \mathrm{dl})$ & Pearson Correlation & $-0.538^{(\$)}$ & $-0.831^{(\$)}$ \\
& Sig. (2-tailed) & 0.000 & 0.000 \\
TC $(\mathrm{mg} / \mathrm{dl})$ & Pearson Correlation & $-0.501^{(\$)}$ & $-0.772^{(\$)}$ \\
& Sig. (2-tailed) & 0.001 & 0.000 \\
Glucose (mg/dl) & Pearson Correlation & $-0.401^{(\$ \$)}$ & $-0.789^{(\$)}$ \\
& Sig. (2-tailed) & 0.010 & 0.000 \\
Insulin $(\mu \mathrm{IU} / \mathrm{dl})$ & Pearson Correlation & $-0.615^{(\$)}$ & $-0.884^{(\$)}$ \\
& Sig. (2-tailed) & 0.000 & 0.000 \\
HOMA-IR & Pearson Correlation & $-0.483^{(\$)}$ & $-0.827^{(\$)}$ \\
& Sig. (2-tailed) & 0.002 & 0.000 \\
OI & Pearson Correlation & $-0.642^{(\$)}$ & $-0.753^{(\$)}$ \\
& Sig. (2-tailed) & 0.000 & 0.000 \\
Adiponectin (ng/dl) & Pearson Correlation & & $0.722^{(\$)}$ \\
& Sig. (2-tailed) & & 0.000 \\
\hline
\end{tabular}

Sig.: significant. (\$): Correlation is significant at the 0.01 level (2-tailed). (\$\$): Correlation is significant at the 0.05 level (2-tailed).

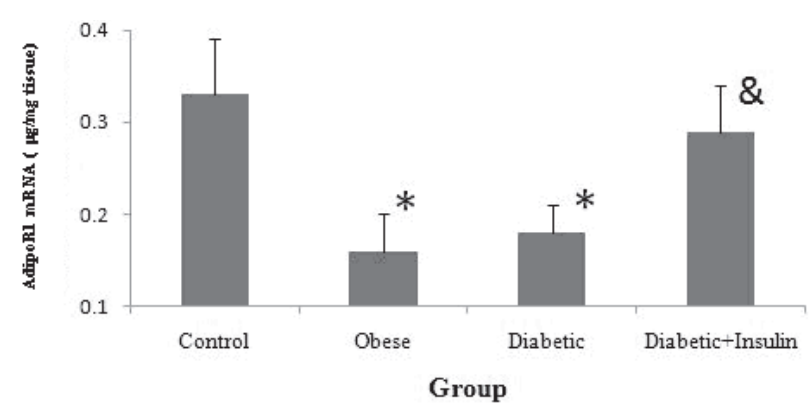

Fig. 2. AdipoR1 in Control Rats and 3 Experimental Rat Groups

Values $(\mu \mathrm{G} / \mathrm{mg}$ tissue) are given as mean \pm S.D. and are statistically significant at $p<0.05 . *$ : Significant compared with the control group. \&: Significant compared with diabetic group.

and adiponectin hormone was significantly positive (Table 2).

\section{DISCUSSION}

In this study we showed that high fat diet caused significant metabolic changes, as compared to the standard laboratory chow. These metabolic changes included an increase in OI, hyperlipidemia, hyperinsulinemia and hyperglycemia, which consequently induced increased IR. In addition, these metabolic changes were accompanied by hypoadiponectinemia and down regulation of AdipoR1 expression in skeletal muscles.

It has been hypothesized that in the steady state, adiponectin level is lower, but its receptors level is higher in obese people than in control subjects so that the high levels of AdipoR1 IR can be compensated in obese subjects. ${ }^{23)}$ Moreover, plasma adiponectin level is inversely correlated to mRNA expression of AdipoR1; the lower the adiponectin plasma level, the higher the expression of the receptors would be. Nevertheless, some other authors suggest that changes in AdipoR1 expression do not always parallel changes in total plasma adiponectin levels. ${ }^{24)}$ In this study we demonstrated that levels of cholesterol, TG and OI were negatively correlated with adiponectin and AdipoR1 expression in skeletal muscles of obese rats. We also showed a positive correlation between plasma adiponectin 
and AdipoR1 expression.

The discrepancy between our results and the observations reported in the literature might be due to the difference in the time length of experiments. Our study only lasted 8 weeks, which might not be long enough for the animals to reach a steady state.

Insulin treatment is among the alternative strategies designed to manage type $2 \mathrm{DM}$ and it results in improvement of glycemic control, insulin synthesis and secretion by $\beta$-cells. ${ }^{25)}$ Insulin therapy decreases hepatic glucose output and improves peripheral glucose uptake and may also improve IR. ${ }^{26}$ ) In our study, insulin treatment resulted in an improvement in IR as manifested by decreasing the fasting plasma lipids, insulin and glucose levels as compared to untreated diabetic group. Insulin also effectively brought both adiponectin and AdipoR1 back to the control levels. This mimics the effect of insulin therapy in humans demonstrated by Langouche ${ }^{27)}$ who observed that insulin therapy increased circulating adiponectin level, normalized the elevated serum C-peptide level and decreased IR by increasing the metabolic insulin signal in human skeletal muscles. It has been shown that administration of insulin to type $2 \mathrm{DM}$ rats noticeably improved the insulin content of $\beta$-cells, with a slight reduction in fasting blood glucose and TG as compared to an untreated diabetic group. ${ }^{25)}$

Despite the significant reduction in glucose level and improvement of IR in insulin-treated diabetic rats as compared to the untreated diabetic rats in our study, the insulin treatment partially restored the glucose level in comparison to the saline controls. Our results may be explained by the work of Mason $^{28)}$ who reported that insulin treatment by an i.p. route normalized the elevated glucose production in streptozotocin-induced diabetic type 2 rats, while insulin delivered by a subcutaneous route only partially normalized it. In addition, the discrepancies between our results and those reported in the literature may also be attributed to different dose of insulin (once instead of twice/day) and short duration of treatment (6 days) applied in our study.

Both obese rats and streptozotocin-induced type 2 diabetic rats had developed similar metabolic abnormalities and increased IR in association with hypoadiponectinemia and down regulation of AdipoR1 expression in skeletal muscles in our study. All these metabolic changes may suggest a link between obesity and type 2 diabetes. Our study also showed that administration of insulin resulted in an increase in both plasma levels of adiponectin and AdipoR1 expression in skeletal muscles. There is a possibility that the improvement in the metabolism containing glucose levels by insulin may induce the restore of adiponectin and AdipoR1. Adiponectin may play a causative role in the development of insulin resistance and the metabolic syndrome. Alternatively, adiponectin secretion may be regulated by insulin, and, therefore, circulating levels may be a marker of insulin resistance and angiopathy, but not a causal factor. There is evidence to suggest that adiponectin is an important contributor to insulin resistance and the metabolic syndrome. ${ }^{29)}$ Therefore, adiponectin and its receptors may offer a novel therapy against obesity and type 2 diabetes.

Acknowledgements This work was supported by grants from the Kasr Al-Aini Research Centre and the grant No.173033 from the Ministry of Science, Republic of Serbia as a collaborative project between Cairo University in Egypt and King Khalid University in Saudi Arabia.

\section{REFERENCES}

1) Lazar, M. A. (2006) The humeral side of insulin resistance. Nat. Med., 12, 43-44.

2) Yamauchi, T., Nio, Y., Maki, T., Kobayashi, M., Takazawa, T., Iwabu, M., Okada-Iwabu, M., Kawamoto, S., Kubota, N., Kubotam, T., Ito, Y., Kamon, J., Tsuchida, A., Kumagai, K., Kozono, H., Hada, Y., Ogata, H., Tokuyama, K., Tsunoda, M., Ide, T., Murakami, K., Awazawa, M., Takamoto, I., Froguel, P., Hara, K., Tobe, K., Nagai, R., Ueki, K. and Kadowaki, T. (2007) Targeted disruption of AdipoR1 and AdipoR2 causes abrogation of adiponectin binding and metabolic actions. Nat. Med., 13, 332-339.

3) Wong, G., Wang, J., Hug, C., Tsao, T. and Lodish, H. (2004) A family of Acrp30/adiponectin structural and functional paralogs. Proc. Natl. Acad. Sci. U.S.A., 101, 10302-10307.

4) Ronti, T., Lupattelli, G. and Mannarino, E. (2006) The endocrine function of adipose tissue: an update. Clin. Endocrinol. (Oxf.), 64, 355-365.

5) Gavrila, A, Peng, C. K., Chan, J. L., Mietus, J. E., Goldberger, A. L. and Mantzoros, C. S. (2003) Diurnal and ultradian dynamics of serum adiponectin in healthy men: comparison with leptin, circulating soluble leptin receptor, and cortisol patterns. J. Clin. Endocrinol. Metab., 88, 2838-2843.

6) Combs, T. P., Berg, A. H., Rajala, M. W., 
Klebanov, S., Iyengar, P., Jimenez-Chillaron, J. C., Patti, M. E., Klein, S. L., Weinstein, R. S. and Scherer, P. E. (2003) Sexual differentiation, pregnancy, calorie restriction, and aging affect the adipocyte-specific secretory protein adiponectin. Diabetes, 52, 268-276.

7) Xu, A., Chan, K. W., Hoo, R. L., Wang, Y., Tan, K. C., Zhang, J., Chen, B., Lam, M. C., Tse, C., Cooper, G. J. and Lam, K. S. (2005) Testosterone selectively reduces the high molecular weight form of adiponectin by inhibiting its secretion from adipocytes. J. Biol. Chem., 280, 18073-18080.

8) Nagao, K., Inoue, N., Wang, Y. and Yanagita, T. (2003) Conjugated linoleic acid enhances plasma adiponectin level and alleviates hyperinsulinemia and hypertension in Zucker diabetic fatty (fa/fa) rats. Biochem. Biophys. Res. Commun., 310, 562-566.

9) Flachs, P., Mohamed-Ali, V., Horakova, O., Rossmeisl, M., Hosseinzadeh-Attar, M. J., Hensler, M., Ruzickova, J. and Kopecky, J. (2006) Polyunsaturated fatty acids of marine origin induce adiponectin in mice fed a high-fat diet. Diabetologia, 49, 394-397.

10) Pischon, T., Girman, C. J., Rifai, N., Hotamisligil, G. S. and Rimm, E. B. (2005) Association between dietary factors and plasma adiponectin concentrations in men. Am. J. Clin. Nutr., 81, 780-786.

11) Yamamoto, Y., Hirose, H., Saito, I., Tomita, M., Taniyama, M., Matsubara, K., Okazaki, Y., Ishii, T., Nishikai, K. and Saruta, I. (2002) Correlation of the adipocyte-derived protein adiponectin with insulin resistance index and serum high-density lipoproteincholesterol, independent of body mass index, in the Japanese population. Clin. Sci., 103, 137-142.

12) Weyer, C., Funahashi, T., Tanaka, S., Hotta, K., Matsuzawa, Y., Pratley, R. E. and Tataranni, P. A. (2001) Hypoadiponectinemia in Obesity and Type 2 Diabetes: Close Association with Insulin Resistance and Hyperinsulinemia. J. Clin. Endocrinol. Metab., 86, 1930-1935.

13) Kadowaki, T. and Yamauchi, T. (2005) Adiponectin and adiponectin receptors. Endocr. Rev., 26, 439451.

14) Henein, H. (2009) Everything about drugs from A to Z. The Complete Drug Reference, vol. 2, Pharmaceutical Press, 88.

15) Sawant, S. P., Dnyanmote, A. V., Shankar, K., Limaye, P. B., Latendresse, J. R. and Mehendale, H. M. (2004) Potentiation of carbon tetrachloride hepatotoxicity and lethality in type 2 diabetic rats. J. Pharmacol. Exp. Ther., 308, 694-704.

16) Trinder, P. (1969) Determination of glucose in blood using glucose oxidase with an alternative oxygen ac- ceptor. Ann. Clin. Biochem., 6, 24.

17) Wahlefeld, A. W. (1974) Triglyceride determination after enzymatic hydrolysis. In Methods of Enzymatic Analysis (Bermeyer, H. U., Eds.), Academic press, New York, pp.18-31.

18) Sundvall, J., Leiviska, J., Alfthan, G. and Vartiainen, E. (2007) Serum cholesterol during 27 years: assessment of systematic error and affecting factors and their role in interpreting population trends. Clin. Chim. Acta., 378, 93-98.

19) Sevillano, J., De Castro, J., Bocos, C., Herrera, E. and Ramos, M. P. (2007) Role of insulin receptor substrate-1 serine 307 phosphorylation and adiponectin in adipose tissue insulin resistance in late pregnancy. Endocrinology, 148, 5933-5942.

20) Dubuis, J. M., Deal, C., Tsagaroulis, P., Clark, R. G. and Van Vliet, G. (1996) Effect of 14 days infusion of growth hormone and/or insulin like growth factor 1 on the obesity of growing zucker rats. Endocrinology, 137, 2799-2806.

21) Matthews, D. R., Hosker, J. P., Rudenski, A. S., Naylor, B. A., Treacher, D. F. and Turner, R. C. (1985) Homeostasis model assessment: insulin resistance and B-cell function from fasting plasma glucose and insulin concentrations in man. Diabetologia., 28, 412-419.

22) Williams, J. (1989) Optimization strategies for the polymerase chain reaction. Biotechniques, 7, 762769.

23) Blüher, M., Bullen, J. W., Lee, J. H., Kralisch, S., Fasshauer, M., Klöting, N., Niebauer, J., Schön, M. R., Williams, C. J. and Mantzoros, C. S. (2006) Circulating adiponectin and expression of adiponectin receptors in human skeletal muscle: associations with metabolic parameters and insulin resistance and regulation by physical training. J. Clin. Endocrinol. Metab., 91, 2310-2316.

24) Beylot, M., Pinteur, C. and Peroni, O. (2006) Expression of the adiponectin receptors AdipoR1 and AdipoR2 in lean rats and in obese Zucker rats. Metabolism, 55, 396-401.

25) Zhou, Y. S., Gao, Y., Guo, X. H., Li, B., Wang, S. and Chi, J. M. (2004) Effects of timely insulin treatment on protection of beta cells in a rat model of type 2 diabetes mellitus. Chin. Med. J., 10, 15231529.

26) Henry, R. R. (1996) Glucose control and insulin resistance in non-insulin-dependent diabetes mellitus. Ann. Intern. Med., 124, 97-103.

27) Langouche, L., Vander Perre, S., Wouters, P. J., D'hoore, A., Hansen, T. K. and Van Den Berghe, G. (2007) Effect of intensive insulin therapy on insulin sensitivity in the critically ill. J. Clin. Endocrinol. 
Metab., 92, 3890-3897.

28) Mason, T., Gupta, N., Goh, T., El-Bahrani, B., Zannis, J., Van De Werve, G. and Giacca, A. (2000) Chronic intraperitoneal insulin delivery, as compared with subcutaneous delivery, improves hepatic glucose metabolism in streptozotocin diabetic rats. Metabolism, 49, 1411-1416.

29) Anastassios, P., Nandini, J. and Andrew, G. (2004) Adipocytokines and Insulin Resistance. J. Clin. Endocrinol. Metab., 89, 2447-2452. 